\title{
Predicting patient-prosthesis mismatch by aortic root evaluation before aortic valve replacement
}

\author{
Koichi Maeda, MD, ${ }^{\mathrm{a}}$ Toru Kuratani, MD, PhD, ${ }^{\mathrm{a}}$ Daisuke Yoshioka, MD, PhD, ${ }^{\mathrm{a}}$ Kyongsun Pak, $\mathrm{PhD},{ }^{\mathrm{b}}$
} Kazuo Shimamura, $\mathrm{MD}, \mathrm{PhD},{ }^{\mathrm{a}}$ Koichi Toda, $\mathrm{MD}, \mathrm{PhD},{ }^{\mathrm{a}}$ and Yoshiki Sawa, $\mathrm{MD}, \mathrm{PhD}^{\mathrm{a}}$

\section{ABSTRACT}

Objective: This study aimed to assess the predictors of patient-prosthesis mismatch (PPM) after surgical aortic valve replacement (SAVR) or transcatheter aortic valve replacement (TAVR) using preoperative computed tomography.

Methods: We enrolled 323 patients undergoing SAVR $(n=85)$ or TAVR $(\mathrm{n}=238)$ for aortic stenosis. The end point was any degree of PPM (effective orifice area index $<0.85 \mathrm{~cm}^{2} / \mathrm{m}^{2}$ ). We assessed the predictors of PPM after SAVR or TAVR and compared the incidence of PPM between both arms. Furthermore, we compared the hemodynamic performance using the propensity score matching.

Results: The occurrence of PPM was significantly higher in the SAVR arm $(24.7 \%$ vs $7.1 \% ; P<.001)$. A small sinotubular junction was an independent predictor of PPM in the SAVR arm (odds ratio, 0.79; $95 \%$ confidence interval, $0.65-0.96 ; P=.015)$, but not a significant predictor in the TAVR arm. In patients with a small sinotubular junction, the prevalence of PPM in the SAVR arm was higher $(57.9 \%$ vs $2.9 \% ; P<.001)$. Furthermore, among the propensity score-matched patients, the incidence of PPM in the SAVR arm was higher than that in the TAVR arm $(26.3 \%$ vs $12.5 \% ; P=.031)$.

Conclusions: In patients with a small sinotubular junction detected by preoperative computed tomography assessment, the incidence of PPM in patients undergoing SAVR was higher. (J Thorac Cardiovasc Surg 2019;158:61-9)

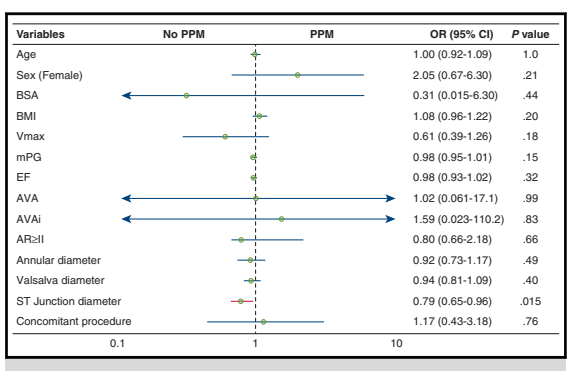

A small sinotubular junction is associated with patient-prosthesis mismatch after surgical AVR.

Central Message

The higher rate of patient-prosthesis mismatch after surgical aortic valve replacement occurred in patients with a small sinotubular junction detected by preoperative computed tomography assessment.

Perspective

Any degree of patient-prosthesis mismatch has been reported to be associated with poor long-term results. Our study revealed that in patients with a sinotubular junction $<22.5 \mathrm{~mm}$ detected by preoperative computed tomography assessment, we should perform certain technical procedures such as aortic root enlargement to allow a larger valve to prevent patient-prosthesis mismatch.

See Commentary on page 70 .
The prevalence of patient-prosthesis mismatch (PPM) after surgical aortic valve replacement (SAVR) or transcatheter aortic valve replacement (TAVR) is reportedly $20 \%$ to $70 \%{ }^{1-3}$ or $10 \%$ to $46 \%,{ }^{1,4}$ respectively. Although any degree of PPM has been demonstrated to be associated with poor long-term results, several studies have argued

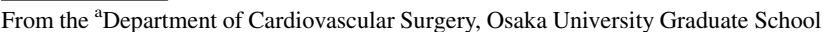
of Medicine, Osaka, Japan; and ${ }^{\mathrm{b}}$ Division of Biostatistics, Department of Data Management, Center for Clinical Research, National Center for Child Health and Development, Tokyo, Japan.

Received for publication Dec 25, 2017; revisions received Nov 8, 2018; accepted for publication Nov 25, 2018; available ahead of print Jan 23, 2019.

Address for reprints: Yoshiki Sawa, MD, PhD, Department of Cardiovascular Surgery, Osaka University Graduate School of Medicine, Yamadaoka 2-2 Suita, Osaka 5650871, Japan (E-mail: sawa-p@surg1.med.osaka-u.ac.jp). $0022-5223 / \$ 36.00$

Copyright (C) 2018 Published by Elsevier Inc. on behalf of The American Association for Thoracic Surgery

https://doi.org/10.1016/j.jtcvs.2018.11.103
}

the predictors of PPM after SAVR or TAVR. $1,3,5,6$ Although PPM correlates with the anatomy of the aortic root, these anatomic predictors have been assessed previously by echocardiographic findings. ${ }^{1,3}$ Recently, electrocardiogram (ECG)-gated multislice computed tomography (MSCT) has been suggested to provide a comprehensive depiction of the aortic root compared with transthoracic echocardiography (TTE) or transesophageal echocardiography (TEE). ${ }^{7,8}$ This study aims to estimate the predictors of PPM after SAVR or TAVR and to

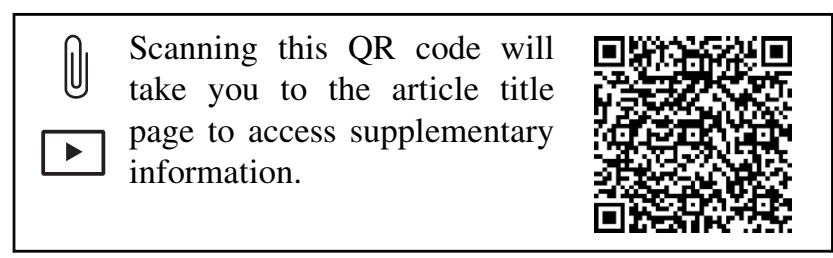




\section{Abbreviations and Acronyms \\ $\mathrm{AR}=$ aortic regurgitation \\ AS = aortic valve stenosis \\ AVA $=$ aortic valve area \\ AVAi $=$ aortic valve area index \\ BSA = body surface area \\ ECG = electrocardiogram \\ EOA $=$ effective orifice area \\ EOAi $=$ effective orifice area index \\ MSCT $=$ multislice computed tomography \\ PPM = patient-prosthesis mismatch \\ SAVR $=$ surgical aortic valve replacement \\ $\mathrm{ST}=$ sinotubular \\ TAVR $=$ transcatheter aortic valve replacement \\ TEE = transesophageal echocardiography \\ TTE $=$ transthoracic echocardiography \\ VinV $=$ valve-in-valve \\ Vmax $=$ maximum velocity}

compare the occurrence of PPM between SAVR arm and TAVR arm using preoperative MSCT.

\section{METHODS \\ Patients}

The Institutional Review Board of Osaka University (Osaka, Japan) approved this study protocol, and we obtained written informed consent from all the patients before enrollment.

Figure 1 summarizes the patient selection for this study. Between October 2009 and December 2015, 644 consecutive patients with severe aortic stenosis (AS) were treated at our institute with SAVR (317 patients) or TAVR (327 patients). From the SAVR arm, we excluded 64 patients with mono- or bicuspid valves, 4 with congenital AS, 13 undergoing redo-SAVR, 3 with mechanical valves, and 104 with incomplete echocardiographic data at discharge or on postoperative day 7. In addition, we excluded 8 patients with SAVR requiring aortic root enlargement and 36 who did not undergo preoperative MSCT. Conversely, regarding TAVR, we excluded 67 patients treated with CoreValve (Medtronic Inc, Minneapolis, Minn; 28 patients), Acurate (Boston Scientific, Mariborough, Mass; 24 patients), Lotus (Boston Scientific; 5 patients), and valve-in-valve (VinV) procedure (10 patients) because of no permission of data use. Moreover, we excluded 5 patients with a bicuspid valve, 10 with incomplete echocardiographic data, and 7 who did not undergo preoperative MSCT. Finally, we enrolled 323 patients (SAVR, 85 patients; TAVR, 238 patients) in this study. We assessed the predictors of PPM after SAVR or TAVR and compared the incidence of PPM between the SAVR arm and TAVR arm. Furthermore, we used propensity score matching to compare the hemodynamic performance.

\section{Definitions of PPM}

In this study, the severity of PPM was graded from echocardiogram using the effective orifice area index (EOAi), with absence defined as $\geq 0.85 \mathrm{~cm}^{2} / \mathrm{m}^{2}$, moderate as $\geq 0.65$ and $<0.85 \mathrm{~cm}^{2} / \mathrm{m}^{2}$, and severe as $<0.65 \mathrm{~cm}^{2} / \mathrm{m}^{2}$.

\section{Study Device and Procedure}

SAVR was performed in accordance with the standard surgical practice through midline sternotomy with cardiopulmonary bypass. The oblique aortotomy and transection of the aorta were performed in $98.8 \%$ and
$1.2 \%$, respectively. Aortic root enlargement was not included in this study. In all patients, bioprostheses were implanted with everting mattress suture with pledget in supra-annular position. On the other hand, regarding TAVR, patients required an agreement that they were ineligible for SAVR because of comorbidities at our heart team's multidisciplinary meetings attended by cardiac surgeons, cardiologists, and anesthesiologists. Before and after reimbursement of Sapien XT in Japan (October 2013), Sapien (THV 9000) and Sapien XT (THV 9300) (Edwards Lifesciences, Irvine, Calif) were implanted. Whereas patients with adequate iliofemoral access underwent TAVR using a Sapien/Sapien XT with Retroflex 3/NovaFlex+ delivery system through a transfemoral approach with standard surgical cut-down of the common femoral artery or common iliac artery, others underwent TAVR with Ascendra/Ascendra+ delivery system by a transapical approach with a mini left-anterior thoracotomy. All the procedures were performed by a heart team comprising cardiac surgeons, cardiologists, and anesthesiologists in a hybrid operating room. Under general anesthesia, balloon aortic valvuloplasty and rapid ventricular pacing were routinely used. Furthermore, TEE was used during the procedures in all cases.

\section{Doppler Echocardiographic Follow-up}

Patients underwent preoperative (baseline) and postoperative (at discharge or on postoperative day 7) Doppler echocardiography, including the aortic jet velocity, mean pressure gradient, aortic valve area (AVA), effective orifice area (EOA), AVA index (AVAi), and EOAi. The EOA was evaluated as the left ventricular outflow tract stroke volume divided by the aortic jet velocity time integral and was indexed for the body surface area (BSA). All the Doppler echocardiographic data associated with TTE to generate accurate baseline and follow-up data comparisons.

\section{Data Acquisition}

Overall, 323 patients (SAVR, 85 patients; TAVR, 238 patients) underwent an ECG-gated MSCT measurement in this study. The 320-Multidetector Computed Tomography Scanner (Aquilion One; Canon Medical Systems, Tochigi, Japan) was used to perform ECGgated MSCT preoperatively. All the computed tomography images were assessed by a dedicated workstation with the 3 mensio valve software (3mensio Medical Imaging BV, Bilthoven, the Netherlands). After the automated reconstruction and segmentation of the aortic root, the annular plane was identified in a perpendicular short-axis view, defined as the plane connecting the nadirs of all 3 aortic cusps. Next, a polygonal line circumscribing a basal ring was traced to define its perimeter. The annulus diameter was evaluated as ([perimeter of the traced polygon]/ $\pi$ ), as described previously at the annular plane in systole. ${ }^{7}$ We defined the sinus of the Valsalva plane as the plane perpendicular to the center line that exhibits the largest cusp dimensions and evaluated the Valsalva diameter as the mean diameter of 3 sinuses in diastole; the sinotubular (ST) junction plane was defined as the distal end of the sinus portion. Furthermore, we evaluated the ST junction diameter as ([perimeter of the traced polygon] $/ \pi$ ) at the ST junction plane in diastole (Figures E1-E3).

\section{End Point}

In this study, the primary end point was moderate or severe PPM (EOAi $<0.85 \mathrm{~cm}^{2} / \mathrm{m}^{2}$ ) because any degree of PPM after SAVR associates with poor long-term results. ${ }^{1,3}$

\section{Statistical Analysis}

Continuous variables are presented as mean \pm standard deviation or median (interquartile range), and categorical variables as frequency (\%). For continuous and categorical variables, comparisons between groups were conducted using the unpaired $t$ test and Fisher exact test, respectively. Logistic regression analysis was performed to examine predictors for PPM. The factors with $P<.20$ were then entered appropriately into a multivariate 


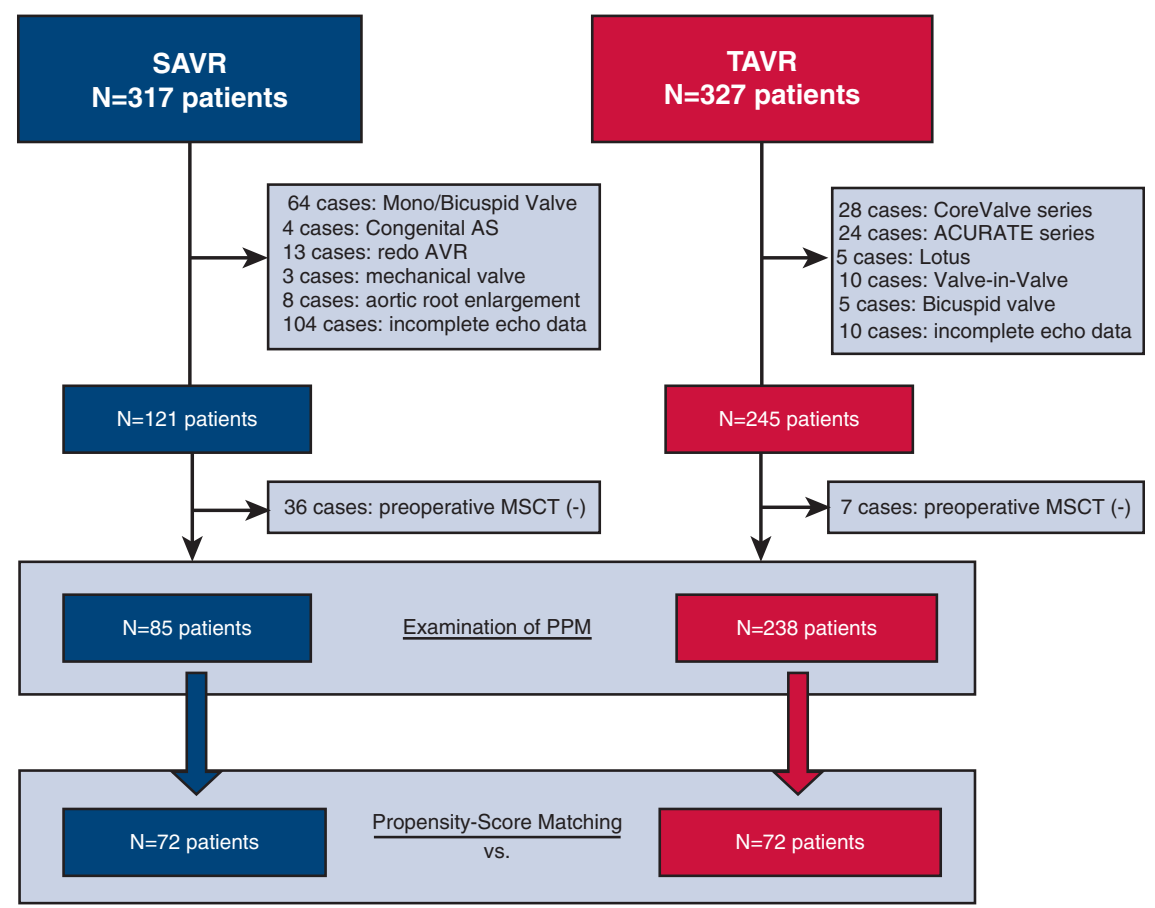

FIGURE 1. Study flowchart. Between October 2009 and December 2015, among 644 consecutive patients (surgical aortic valve replacement [SAVR], 317 patients; transcatheter aortic valve replacement [TAVR], 327 patients) with severe aortic valve stenosis $(A S)$ ), 323 patients (SAVR, 85 patients; TAVR, 238 patients) were enrolled in the study. We assessed the predictors of patient-prosthesis mismatch (PPM) after SAVR or TAVR and compared the incidence of PPM between the SAVR arm and TAVR arm. Furthermore, we used the propensity score matching to compare hemodynamic performance. $A V R$, aortic valve replacement; MSCT, multislice computed tomography.

model. A nonparametric receiver-operating-characteristic curve was constructed to show various cutoff values for the anatomic characteristics of aortic root (annular diameter, Valsalva diameter, and ST junction diameter) for evaluating the discrimination of PPM. Propensity score matching (1:1 matching, with the nearest neighbor matching without replacement) was performed to adjust for significant differences in baseline covariates and potential confounders that may lead to biased estimates between the SAVR and TAVR arms. A propensity score for each patient was calculated by performing a nonparsimonious multivariable logistic regression, with the type of intervention as the end point (SAVR coded as 0 , and TAVR as 1). All variables that were significantly different at baseline and that might influence the choice of SAVR versus TAVR were considered: sex, BSA, maximum velocity (Vmax), AVAi, annulus diameter, Valsalva diameter, and ST junction diameter. Standardized differences before and after propensity matching of each variable were used to evaluate the magnitude of the difference between the 2 arms. After propensity score matching, for continuous and categorical variables, comparisons of bioprosthetic performances between groups were conducted using the paired $t$ test and McNemar test. SPSS version 22.0 (IBM-SPSS Inc, Armonk, NY) was used to perform all statistical analyses.

\section{RESULTS}

In this study, we enrolled 323 patients with AS, including 85 undergoing SAVR (mean age, $75.9 \pm 5.7$ years; $64.7 \%$ women) and 238 undergoing TAVR (mean age, $83.0 \pm 6.0$ years; $64.7 \%$ women) between October 2009 and March 2015. Table 1 summarizes the comparison of baseline characteristics. The patients in the SAVR arm were significantly younger $(P<.001)$, larger in body size $\left(\right.$ BSA $=$ SAVR:TAVR, $1.49 \pm 0.17: 1.43 \pm 0.17 \mathrm{~m}^{2}$; $P=.006$ ), had larger AVA (SAVR:TAVR, $0.75 \pm$ $\left.0.18: 0.68 \pm 0.18 \mathrm{~cm}^{2} ; P=.004\right)$, and had better left ventricular function (SAVR:TAVR, 65.5\% $\pm 10.3 \%: 61.5 \% \pm$ $13.3 \% ; P=.012$ ) compared with the patients in the TAVR arm. We observed no significant difference between both arms in the annular diameter, Valsalva diameter, and ST junction diameter on preoperative MSCT findings. Table 2 presents the operative results. In the SAVR arm, Mosaic valves (Medtronic Inc, Minneapolis, Minn) were most frequently used in $38.8 \%$ of patients, and a prosthetic valve with the smallest label size $(19 \mathrm{~mm})$ was used in $44.7 \%$. However, in the TAVR arm, the smallest transcatheter valve $(20 \mathrm{~mm}$ Sapien XT) was implanted in 1 patient only $(0.4 \%)$. The postoperative echocardiographic findings at discharge or on postoperative day 7 revealed that the Vmax, mean pressure gradient, EOA, and EOAi in the TAVR arm were better compared with the SAVR arm $(P<.001)$. However, postoperative aortic regurgitation (AR) grade, including the paravalvular leak in the SAVR arm was significantly less than that in the TAVR arm (AR $\geq$ II, $7.1 \%$ vs $44.1 \% ; P<.001$ ). In addition, the incidence of moderate or severe PPM (EOAi $<0.85 \mathrm{~cm}^{2} / \mathrm{m}^{2}$ ) was significantly higher in the SAVR arm $(24.7 \%$ vs $7.1 \% ; P<.001)$ than the TAVR arm. Furthermore, 
TABLE 1. Baseline characteristics

\begin{tabular}{|c|c|c|c|c|}
\hline Characteristic & $\begin{array}{c}\text { SAVR } \\
(n=85)\end{array}$ & $\begin{array}{c}\text { TAVR } \\
(\mathbf{n}=\mathbf{2 3 8})\end{array}$ & $P$ value & Standardized difference \\
\hline Age (y) & $75.9 \pm 5.7$ & $83.0 \pm 6.0$ & $<.001$ & 1.21 \\
\hline Female sex & $55(64.7)$ & $154(64.7)$ & 1.0 & 0 \\
\hline $\operatorname{BSA}\left(\mathrm{m}^{2}\right)$ & $1.49 \pm 0.17$ & $1.43 \pm 0.17$ & .0060 & 0.35 \\
\hline BMI & $22.3 \pm 3.9$ & $21.6 \pm 3.3$ & .082 & 0.19 \\
\hline \multicolumn{5}{|l|}{ Echocardiographic findings } \\
\hline $\operatorname{Vmax}(\mathrm{m} / \mathrm{s})$ & $4.6 \pm 0.7$ & $4.5 \pm 0.7$ & .46 & 0.14 \\
\hline $\mathrm{mPG}(\mathrm{mm} \mathrm{Hg})$ & $52.3 \pm 16.8$ & $50.0 \pm 17.5$ & .31 & 0.13 \\
\hline $\operatorname{AVA}\left(\mathrm{cm}^{2}\right)$ & $0.75 \pm 0.18$ & $0.68 \pm 0.18$ & .0040 & 0.39 \\
\hline AVAi $\left(\mathrm{cm}^{2} / \mathrm{m}^{2}\right)$ & $0.51 \pm 0.12$ & $0.48 \pm 0.12$ & .086 & 0.25 \\
\hline $\mathrm{AR}$ grade $\geq \mathrm{II}$ & $52(61.2)$ & $177(74.4)$ & .026 & 0.26 \\
\hline $\mathrm{EF}(\%)$ & $65.5 \pm 10.3$ & $61.5 \pm 13.3$ & .012 & 0.34 \\
\hline \multicolumn{5}{|l|}{ ECG-gated MSCT findings } \\
\hline Annular diameter (mm) & $23.2 \pm 2.2$ & $22.9 \pm 1.8$ & .32 & 0.15 \\
\hline Valsalva diameter $(\mathrm{mm})$ & $29.3 \pm 3.7$ & $29.5 \pm 2.7$ & .67 & 0.062 \\
\hline Sinotubular junction diameter $(\mathrm{mm})$ & $25.1 \pm 3.3$ & $25.1 \pm 2.7$ & .89 & 0 \\
\hline
\end{tabular}

Values are presented as $\mathrm{n}(\%)$ or mean \pm standard deviation. $S A V R$, Surgical aortic valve replacement; TAVR, transcatheter aortic valve replacement; $B S A$, body surface area; $B M I$, body mass index; Vmax, max velocity; $m P G$, mean pressure gradient; $A V A$, aortic valve area; $A V A i$, aortic valve area index; $A R$, aortic regurgitation; $E F$, ejection fraction; $E C G$, electrocardiogram; $M S C T$, multislice computed tomography.

all-cause mortality at 1-year in the SAVR and TAVR arms was $98.8 \%$ and $90.9 \%$, respectively.

Table E1 presents the annulus diameter on computed tomography findings and the incidence of PPM in each kind of prosthetic valve. In the analysis, PPM frequently occurred in the Mosaic (30.3\%), Carpentier-Edwards Perimount (Edwards Lifesciences, Irvine, Calif) $(22.7 \%)$, and Mitroflow (Sorin Group Inc, Saluggia, Italy) (28.6\%) valves. Figure 2 shows odds ratios of the baseline characteristics including anatomy of aortic root on computed tomography findings for the incidence of PPM in the SAVR and TAVR arms, respectively. In the SAVR arm, the logistic regression analysis revealed that PPM was not considerably different regarding age, sex, BSA, body mass index, and severity of AS, including the aortic jet velocity, mean pressure gradient, AVA, and AVAi. However, PPM was significantly related to a small ST junction diameter (odds ratio, $0.79 ; 95 \%$ confidence interval, $0.65-0.96 ; P=.015$ ). Furthermore, multivariate logistic regression revealed that a small ST junction was an independent predictor of PPM (odds ratio, 0.76; 95\% confidence interval, $0.62-0.93 ; P=.0029)$. In the receiver-operating-characteristic analysis (Figures E4-E9), the cutoff value of $22.5 \mathrm{~mm}$ in the ST junction diameter on the MSCT findings exhibited the highest sum of sensitivity $(87.5 \%)$ and specificity $(52.4 \%$; area under the curve, 0.71). In the TAVR arm, on the other hand, no significant difference was observed in baseline characteristics, including the severity of AS and anatomy of the aortic root on the MSCT. Table E2 presents baseline characteristics of patients in the TAVR and SAVR arms based on the presence or absence of PPM.

\section{Comparison of the Bioprosthetic Valve Performance in the TAVR and SAVR Arms Based on ST Junction Diameter $(<\mathbf{2 2 . 5} \mathbf{~ m m}$ or $\geq \mathbf{2 2 . 5} \mathbf{~ m m})$}

In the SAVR arm, small surgical bioprostheses $(19 \mathrm{~mm})$ were more frequently used in patients with a small ST junction $(<22.5 \mathrm{~mm}) ; 79.0 \%$ versus $34.9 \%(P=.001)$ and exhibited a significantly higher incidence of PPM $(57.9 \%$ vs $15.2 \% ; P<.001$ (Table 3). Furthermore, the prosthetic jet velocity and mean pressure gradient were higher and EOAi was smaller in patients with a small ST junction $(<22.5 \mathrm{~mm})$ compared with those in patients with a $S T$ junction $\geq 22.5 \mathrm{~mm}$. Conversely, regarding the TAVR arm, although a relatively smaller EOA was found in a small ST junction, we observed no significant difference in bioprosthesis hemodynamic performances between ST junction $<22.5 \mathrm{~mm}$ and $\geq 22.5 \mathrm{~mm}$. Furthermore, in patients with a small ST junction $(<22.5 \mathrm{~mm} ; \mathrm{n}=53$; SAVR, 19 patients; TAVR, 34 patients), the incidence of PPM was significantly higher in the SAVR $(57.9 \%$ vs $2.9 \% ; P<.001)$ (Table 4$)$ than TAVR.

\section{Comparison of the Bioprosthesis Valve Performance in the TAVR and SAVR Arms after the Propensity Score Matching}

We observed no significant differences in baseline characteristics between both arms after the propensity score matching regarding sex, BSA, Vmax, AVAi, annulus diameter, Valsalva diameter, and ST junction diameter (Figure 1 and Table 5). Comparison of the standardized differences of covariates between before and after propensity matching (Table 1 and Table 5, respectively) 
TABLE 2. Operative results

\begin{tabular}{|c|c|c|c|}
\hline & $\begin{array}{c}\text { SAVR } \\
(\mathbf{n}=\mathbf{8 5})\end{array}$ & $\begin{array}{c}\text { TAVR } \\
(\mathbf{n}=\mathbf{2 3 8})\end{array}$ & $\begin{array}{c}P \\
\text { value }\end{array}$ \\
\hline \multicolumn{4}{|l|}{ Device used* } \\
\hline Mosaic & $33(38.8)$ & - & \\
\hline CEP & $22(25.9)$ & - & \\
\hline Epic & $12(14.1)$ & - & - \\
\hline Trifecta & $11(12.9)$ & - & \\
\hline Mitroflow & $7(8.2)$ & - & \\
\hline Sapien & - & $41(17.2)$ & \\
\hline Sapien XT & - & $197(82.8)$ & \\
\hline \multicolumn{4}{|l|}{ Valve size (mm) } \\
\hline 19 & $38(44.7)$ & - & \\
\hline 20 & - & $1(0.4)$ & \\
\hline 21 & $36(42.4)$ & - & - \\
\hline 23 & $9(10.6)$ & $143(60.1)$ & \\
\hline 25 & $2(2.4)$ & - & \\
\hline 26 & - & 87 (36.6) & \\
\hline 29 & - & $7(2.9)$ & \\
\hline \multicolumn{4}{|l|}{ Procedure-related variables } \\
\hline \multicolumn{4}{|l|}{ Aortotomy } \\
\hline Oblique aortotomy & $84(98.8)$ & - & - \\
\hline Transection & $1(1.2)$ & - & - \\
\hline Concomitant procedure & $34(40.0)$ & 7 (2.9) & $<.001$ \\
\hline \multicolumn{4}{|c|}{ Postoperative echocardiography findings } \\
\hline $\operatorname{Vmax}(\mathrm{m} / \mathrm{s})$ & $2.6 \pm 0.5$ & $2.1 \pm 0.4$ & $<.001$ \\
\hline mPG (mm Hg) & $15.0 \pm 5.3$ & $9.4 \pm 3.4$ & $<.001$ \\
\hline $\operatorname{EOA}\left(\mathrm{cm}^{2}\right)$ & $1.48 \pm 0.34$ & $1.70 \pm 0.39$ & $<.001$ \\
\hline EOAi $\left(\mathrm{cm}^{2} / \mathrm{m}^{2}\right)$ & $1.00 \pm 0.21$ & $1.20 \pm 0.26$ & $<.001$ \\
\hline AR grade & & & $<.001$ \\
\hline 0 & $50(58.8)$ & $42(17.7)$ & \\
\hline I & $29(34.1)$ & $91(38.2)$ & \\
\hline II & $6(7.1)$ & 99 (41.6) & \\
\hline III & $0(0)$ & $5(2.1)$ & \\
\hline IV & $0(0)$ & $1(0.4)$ & \\
\hline PPM & $21(24.7)$ & $17(7.1)$ & $<.001$ \\
\hline Moderate PPM & $20(23.5)$ & $17(7.1)$ & $<.001$ \\
\hline Severe PPM & $1(1.2)$ & $0(0)$ & .26 \\
\hline \multicolumn{4}{|l|}{ Clinical results } \\
\hline Operative mortality & $0(0)$ & $1(0.4)$ & 1.0 \\
\hline Hospital mortality & $1(1.2)$ & $2(0.8)$ & 1.0 \\
\hline 1-y survival & 98.8 & 90.9 & .020 \\
\hline
\end{tabular}

Values are presented as $\mathrm{n}(\%)$, mean \pm standard deviation, or \%. SAVR, Surgical aortic valve replacement; TAVR, transcatheter aortic valve replacement; $C E P$, Carpentier-Edwards Perimount; Vmax, max velocity; $m P G$, mean pressure gradient; EOA, effective orifice area; EOAi, effective orifice area index; $A R$, aortic regurgitation; $P P M$, patient-prosthesis mismatch. ${ }^{*}$ Device manufacturers: Mosaic: Medtronic Inc, Minneapolis, Minn; CEP: Edwards Lifesciences, Irvine, Calif; Epic Valve: Abbott-St Jude Medical, St Paul, Minn; Trifecta Valve: Abbott-St Jude Medical; Mitroflow: Sorin Group Inc, Saluggia, Italy; Sapien: Edwards Lifesciences; Sapien XT: Edwards Lifesciences.

confirmed that the distribution of baseline covariates after matching would be balanced between SAVR and TAVR arms. Although postoperative AR (including paravalvular leak) in the TAVR arm was significantly greater than that in the SAVR arm $(P<.001)$, EOAi in the TAVR arm was significantly superior to those in the SAVR arm
$(1.17 \pm 0.30$ vs $0.99 \pm 0.21 ; P<.001)$, and the incidence of PPM in the SAVR arm was significantly higher than that in the TAVR arm $(26.3 \%$ vs $12.5 \% ; P=.031)$ (Table 6).

\section{DISCUSSION}

PPM is applied to conditions in which the EOA of the prosthesis is physiologically too small regarding the patient's body size. ${ }^{9}$ The rate of any degree of PPM after SAVR or TAVR is reportedly $20 \%$ to $70 \%{ }^{1-3}$ or $10 \%$ to $46 \%,{ }^{1,4}$ respectively. These rates are almost same as those of this study $(24.7 \%$ in the SAVR arm and $7.1 \%$ in the TAVR arm). Although the correlation between PPM and survival remains debatable, any degree of PPM after initial SAVR has been reported to be associated with poor long-term results from the Society of Thoracic Surgeons Adult Cardiac Surgery Database ${ }^{3}$ and the Placement of Aortic Transcatheter Valve 1 trial cohort A. ${ }^{1}$ Although several studies have mentioned that PPM after SAVR or TAVR correlated with patients' preoperative characteristics, including age (older), sex (female), body size, hypertension, diabetes, and renal failure, ${ }^{1,4-6}$ these studies barely considered the anatomy of the aortic root, which is vital in SAVR and TAVR. In contrast, several studies reported a correlation between the incidence of PPM and the small annulus diameter after SAVR or TAVR ${ }^{1,3}$; the diameter was evaluated by echocardiographic findings. Recently, ECG-gated MSCT was reported to offer a comprehensive depiction of the aortic root, including the Valsalva sinuses, cusps, and the aortic annulus compared with TTE or TEE. ${ }^{7,8}$ To the best of our knowledge, this is the first investigation on using MSCT for the precise determination of anatomical predictors of PPM after SAVR or TAVR.

SAVR has played a vital role as the gold standard treatment for AS even in the TAVR era. Reportedly, bioprostheses have undergone remarkable changes, providing good results with long durability. ${ }^{10,11}$ In addition, the incidence of PPM after SAVR has reduced considerably from the Society of Thoracic Surgeons Adult Cardiac Surgery Database. Fallon and colleagues ${ }^{3}$ reported that this likely reflects a combination of improved awareness within the literature toward avoiding severe PPM combined with generational improvements in valve technology. Because these improvements in the bioprosthetic valve technology resulted in the indication for younger patients with AS, it is compulsory to reconsider SAVR in the TAVR era, especially in younger patients with AS who have the potential to undergo redo-SAVR in the future. Thus, this study could be useful for detecting an optimal surgical bioprosthesis that might affect good results of VinV in the future because this procedure seems intensely related to an initial bioprosthesis; besides, the clinical outcomes of VinV were reported to be worse in 
SAVR

\begin{tabular}{|c|c|c|c|c|}
\hline Variables & No PPM & PPM & OR $(95 \% \mathrm{Cl})$ & $P$ value \\
\hline Age & & & $1.00(0.92-1.09)$ & 1.0 \\
\hline Sex (Female) & & & $2.05(0.67-6.30)$ & .21 \\
\hline BSA & & & $0.31(0.015-6.30)$ & .44 \\
\hline BMI & & & $1.08(0.96-1.22)$ & .20 \\
\hline Vmax & & & $0.61(0.39-1.26)$ & .18 \\
\hline $\mathrm{mPG}$ & & & $0.98(0.95-1.01)$ & .15 \\
\hline EF & & & $0.98(0.93-1.02)$ & .32 \\
\hline AVA & & & $1.02(0.061-17.1)$ & .99 \\
\hline AVAi & & & $1.59(0.023-110.2)$ & .83 \\
\hline$A R \geq I I$ & & & $0.80(0.66-2.18)$ & .66 \\
\hline Annular diameter & & & $0.92(0.73-1.17)$ & .49 \\
\hline Valsalva diameter & & & $0.94(0.81-1.09)$ & .40 \\
\hline ST Junction diameter & & & $0.79(0.65-0.96)$ & .015 \\
\hline Concomitant procedure & & & $1.17(0.43-3.18)$ & .76 \\
\hline
\end{tabular}

TAVR

\begin{tabular}{|c|c|c|c|c|}
\hline Variables & No PPM & PPM & OR (95\% Cl) & $P$ value \\
\hline Age & & & $1.00(0.92-1.09)$ & .95 \\
\hline Sex (Female) & & & $1.34(0.45-3.93)$ & .60 \\
\hline BSA & & & $11.0(0.57-214.0)$ & .11 \\
\hline BMI & & & $1.06(0.91-1.23)$ & .46 \\
\hline Vmax & & & $1.11(0.58-2.14)$ & .75 \\
\hline $\mathrm{mPG}$ & & & $1.00(0.98-1.03)$ & .82 \\
\hline EF & & & $0.99(0.95-1.02)$ & .47 \\
\hline AVA & -0 & & $0.37(0.023-5.73)$ & .47 \\
\hline$A \vee A i$ & & & $0.040(0.0010-2.82)$ & .14 \\
\hline$A R \geq I I$ & & & $1.66(0.46-5.99)$ & .44 \\
\hline Annular diameter & & & $0.92(0.61-1.11)$ & .20 \\
\hline Valsalva diameter & & & $0.90(0.74-1.09)$ & .27 \\
\hline ST Junction diameter & & & $1.04(0.86-1.25)$ & .69 \\
\hline
\end{tabular}

FIGURE 2. Logistic regression analysis to determine the predictors of patient-prosthesis mismatch $(P P M)$ after transcatheter aortic valve replacement $(T A V R)$ or surgical aortic valve replacement $(S A V R)$. Odds ratios $(O R S)$ of the baseline characteristics, including anatomy of aortic root on computed tomography findings for the incidence of PPM in the SAVR and TAVR arms. In the SAVR arm, the logistic regression analysis revealed that a small sinotubular (ST) junction was significantly related to PPM. In the TAVR arm, no significant difference was observed in baseline characteristics, including the severity of aortic stenosis and anatomy of the aortic root. $C I$, Confidence interval; BSA, body surface area; BMI, body mass index; Vmax, maximum velocity; $m P G$, mean pressure gradient; $E F$, ejection fraction; $A V A$, aortic valve area; $A V A i$, aortic valve area index; $A R$, aortic regurgitation.

patients with small surgical bioprostheses (label size $<21 \mathrm{~mm}) .{ }^{12,13}$ Regarding the anatomic characteristics assessed by MSCT in this study, a small ST junction $(<22.5 \mathrm{~mm})$ was an independent predictor of PPM after SAVR, which could be adequately elucidated by the fact that because a larger surgical bioprosthesis cannot pass through a small ST junction in SAVR under the usual aortotomy, smaller valves are typically selected, resulting in smaller EOAi. Thus, if a patient has a small aortic root (ST junction $<22.5 \mathrm{~mm}$ ), surgeons should consider some 
TABLE 3. Comparison of the bioprosthetic valve performance in the transcatheter aortic valve replacement (TAVR) and surgical aortic valve replacement (SAVR) arms according to sinotubular junction (STJ) diameter $<22.5 \mathrm{~mm}$ or $\geq 22.5 \mathrm{~mm}$

\begin{tabular}{|c|c|c|c|c|c|c|}
\hline \multirow[b]{2}{*}{ Parameter } & \multicolumn{3}{|c|}{ SAVR $(\mathbf{n}=\mathbf{8 5})$} & \multicolumn{3}{|c|}{$\operatorname{TAVR}(\mathrm{n}=238)$} \\
\hline & $\overline{\text { STJ }<22.5(n=19)}$ & STJ $\geq 22.5(n=66)$ & $P$ value & $\overline{\text { STJ }<22.5(n=34)}$ & STJ $\geq 22.5(n=204)$ & $P$ value \\
\hline $\operatorname{Vmax}(\mathrm{m} / \mathrm{s})$ & $2.8 \pm 0.4$ & $2.5 \pm 0.5$ & .050 & $2.1 \pm 0.4$ & $2.1 \pm 0.4$ & .74 \\
\hline mPG (mm Hg) & $17.4 \pm 5.4$ & $14.4 \pm 5.1$ & .030 & $10.0 \pm 3.2$ & $9.3 \pm 3.4$ & .30 \\
\hline $\mathrm{EOA}\left(\mathrm{cm}^{2}\right)$ & $1.28 \pm 0.30$ & $1.54 \pm 0.33$ & .002 & $1.56 \pm 0.23$ & $1.72 \pm 0.41$ & .027 \\
\hline EOAi $\left(\mathrm{cm}^{2} / \mathrm{m}^{2}\right)$ & $0.87 \pm 0.18$ & $1.04 \pm 0.20$ & .002 & $1.20 \pm 0.22$ & $1.20 \pm 0.27$ & .90 \\
\hline $\begin{array}{l}\text { AR grade } \\
0 \\
\text { I } \\
\text { II } \\
\text { III } \\
\text { IV }\end{array}$ & $\begin{array}{c}14(73.7) \\
5(26.3) \\
0(0) \\
0(0) \\
0(0)\end{array}$ & $\begin{array}{c}36(54.6) \\
24(36.4) \\
6(9.0) \\
0(0) \\
0(0)\end{array}$ & .11 & $\begin{aligned} 5 & (14.7) \\
12 & (35.3) \\
14 & (41.2) \\
2 & (5.9) \\
1 & (2.9)\end{aligned}$ & $\begin{array}{c}37(18.1) \\
79(38.7) \\
85(41.7) \\
3(1.5) \\
0(0)\end{array}$ & .19 \\
\hline \multicolumn{7}{|l|}{ End point } \\
\hline PPM & $11(57.9)$ & $10(15.2)$ & $<.001$ & $1(2.9)$ & $16(7.8)$ & .48 \\
\hline $19 \mathrm{~mm}$ & $15(79.0)$ & $23(34.9)$ & .001 & - & - & - \\
\hline $20 \mathrm{~mm}$ & - & - & - & $0(0)$ & $1(0.49)$ & 1.0 \\
\hline
\end{tabular}

Values are presented as n $(\%)$ or mean \pm standard deviation. SAVR, Surgical aortic valve replacement; TAVR, transcatheter aortic valve replacement; STJ, sinotubular junction; $V m a x$, maximum velocity; $m P G$, mean pressure gradient; $E O A$, effective orifice area; $E O A i$, effective orifice area index; $A R$, aortic regurgitation; $P P M$, patient-prosthesis mismatch.

kinds of aortotomy, including the extending J-aortotomy below the ST junction, transecting the aorta, or aortic root enlargement such as Nicks method to descend a larger bioprosthesis. Furthermore, suture technique (including simple interrupted suture or semicontinuous suture) or the use of sutureless valve should be considered.

TABLE 4. Comparison of bioprosthesis performance between the surgical aortic valve replacement (SAVR) and transcatheter aortic valve replacement (TAVR) arms in patients with a small sinotubular junction (STJ) $(<22.5 \mathrm{~mm})$

\begin{tabular}{lccc}
\hline & \multicolumn{3}{c}{ STJ $<\mathbf{2 2 . 5}(\mathbf{n}=\mathbf{5 3})$} \\
\cline { 2 - 4 } \multicolumn{1}{c}{ Parameter } & SAVR $(\mathbf{n}=\mathbf{1 9})$ & TAVR $(\mathbf{n}=\mathbf{3 4})$ & $\boldsymbol{P}$ value \\
\hline Vmax $(\mathrm{m} / \mathrm{s})$ & $2.8 \pm 0.4$ & $2.1 \pm 0.4$ & $<.001$ \\
$\mathrm{mPG}(\mathrm{mm} \mathrm{Hg})$ & $17.4 \pm 5.4$ & $10.0 \pm 3.2$ & $<.001$ \\
EOA $\left(\mathrm{cm}^{2}\right)$ & $1.28 \pm 0.30$ & $1.56 \pm 0.23$ & $<.001$ \\
EOAi $\left(\mathrm{cm}^{2} / \mathrm{m}^{2}\right)$ & $0.87 \pm 0.18$ & $1.20 \pm 0.22$ & $<.001$ \\
AR grade & & & $<.001$ \\
0 & $14(73.7)$ & $5(14.7)$ & \\
I & $5(26.3)$ & $12(35.3)$ & \\
II & $0(0)$ & $14(41.2)$ & \\
III & $0(0)$ & $2(5.9)$ & \\
IV & $0(0)$ & $1(2.9)$ & \\
PPM & $11(57.9)$ & $1(2.9)$ & $<.001$ \\
$19 \mathrm{~mm}$ & $15(79.0)$ & - & - \\
$20 \mathrm{~mm}$ & - & $0(0)$ & - \\
\hline VI & &
\end{tabular}

Values are presented as $\mathrm{n}(\%)$ or mean \pm standard deviation. STJ, Sinotubular junction; SAVR, surgical aortic valve replacement; TAVR, transcatheter aortic valve replacement; Vmax, maximum velocity; $m P G$, mean pressure gradient; $E O A$, effective orifice area; $E O A i$, effective orifice area index; $A R$, aortic regurgitation; $P P M$, patient-prosthesis mismatch.
The rate of $19-\mathrm{mm}$ bioprostheses $(44.7 \%)$ in the SAVR arm of this study was higher than that of Westen countries. ${ }^{3}$ However, accorging to the Japan Cardiovascular Surgery Database, ${ }^{14}$ among 16,272 patients undergoing SAVR, not only the rate of a use of $19 \mathrm{~mm}$ or $<19 \mathrm{~mm}$ prostheses $(45.3 \%)$ but also the mean BSA $\left(1.53 \mathrm{~m}^{2}\right)$ were almost same as those of this study (mean BSA in this study, $1.49 \mathrm{~m}^{2}$ ). From these points, the SAVR arm in this study does not represent a typical patient population in Western countries; nevertheless, this study could be useful for the occasional smaller patient that surgeons in Western countries must encounter.

In recent years, TAVR has reoriented the treatment of patients with AS based on not only early but also midterm outcomes $^{15-18}$ in Western countries; that is, although at first, TAVR for AS was recommended in inoperable or high-surgical-risk patients, ${ }^{17,18}$ it now tends to be indicated even in intermediate-surgical-risk patients. ${ }^{19,20}$ Several studies have reported that PPM after TAVR correlated with larger body size (BSA and body mass index) ${ }^{1,4}$ whereas larger BSA correlated with an increased risk of PPM without attaining statistical significance in this study.

Furthermore, some other studies reported that transcatheter aortic bioprostheses provide superior hemodynamic performance than surgical aortic bioprostheses do on TTE or TEE assessments, because the transcatheter heart valve was implanted inside the native valve by the balloon/self-expanding nature; larger EOA might be obtained compared with surgical bioprostheses, which were typically implanted on the annulus (supra-annular position). ${ }^{1,21}$ After the propensity score 
TABLE 5. Baseline characteristics after the propensity-score matching

\begin{tabular}{|c|c|c|c|c|}
\hline Characteristic & $\begin{array}{c}\text { SAVR } \\
(n=72)\end{array}$ & $\begin{array}{c}\text { TAVR } \\
(n=72)\end{array}$ & $P$ value & Standardized difference \\
\hline Age (y) & $76.2 \pm 5.3$ & $82.2 \pm 6.3$ & $<.001$ & 1.02 \\
\hline Female sex & $46(63.9)$ & $46(63.9)$ & 1.0 & 0 \\
\hline $\operatorname{BSA}\left(\mathrm{m}^{2}\right)$ & $1.47 \pm 0.16$ & $1.47 \pm 0.17$ & .82 & 0.037 \\
\hline BMI & $22.0 \pm 3.6$ & $22.1 \pm 3.1$ & .83 & 0.036 \\
\hline \multicolumn{5}{|l|}{ Echocardiography findings } \\
\hline $\operatorname{Vmax}(\mathrm{m} / \mathrm{s})$ & $4.5 \pm 0.7$ & $4.7 \pm 0.8$ & .28 & 0.18 \\
\hline mPG (mm Hg) & $51.5 \pm 16.8$ & $53.1 \pm 19.2$ & .60 & 0.088 \\
\hline AVA $\left(\mathrm{cm}^{2}\right)$ & $0.73 \pm 0.18$ & $0.69 \pm 0.18$ & .26 & 0.19 \\
\hline AVAi $\left(\mathrm{cm}^{2} / \mathrm{m}^{2}\right)$ & $0.50 \pm 0.11$ & $0.47 \pm 0.11$ & .14 & 0.25 \\
\hline $\mathrm{AR}$ grade $\geq \mathrm{II}$ & $44(61.1)$ & $50(69.4)$ & 1.0 & 0.18 \\
\hline $\mathrm{EF}(\%)$ & $65.0 \pm 10.7$ & $62.8 \pm 12.5$ & .25 & 0.19 \\
\hline \multicolumn{5}{|l|}{ ECG-gated MSCT findings } \\
\hline Annular diameter (mm) & $23.0 \pm 2.1$ & $23.2 \pm 1.9$ & .71 & 0.062 \\
\hline Valsalva diameter $(\mathrm{mm})$ & $29.5 \pm 3.6$ & $29.5 \pm 3.1$ & .91 & 0.019 \\
\hline Sinotubular junction diameter $(\mathrm{mm})$ & $25.1 \pm 3.2$ & $25.2 \pm 2.9$ & .96 & 0.0075 \\
\hline
\end{tabular}

Values are presented as $\mathrm{n}(\%)$ or mean \pm standard deviation. SAVR, Surgical aortic valve replacement; TAVR, transcatheter aortic valve replacement; $B S A$, body surface area; $B M I$, body mass index; Vmax, maximum velocity; $m P G$, mean pressure gradient; $A V A$, aortic valve area; $A V A i$, aortic valve area index; $A R$, aortic regurgitation; $E F$, ejection fraction, ECG, electrocardiogram; MSCT, multislice computed tomography.

matching based on MSCT findings, this study also showed that transcatheter heart valves (Sapien/Sapien XT) provided superior hemodynamic performance compared with surgical bioprostheses. However, the higher incidence of AR (including paravalvular leak) occurred in the TAVR arm in this study. This was considered to be caused by the Sapien/Sapien XT, which is not used today. The incidence of AR after TAVR has been improved by the development of transcatheter heart valves, ${ }^{22}$ that is still higher incidence. If this problem of TAVR is further

TABLE 6. Comparison of bioprosthesis performance after the propensity-score matching

\begin{tabular}{lccc}
\hline \multicolumn{1}{c}{ Parameter } & SAVR $(\mathbf{n}=\mathbf{7 2})$ & TAVR $(\mathbf{n}=\mathbf{7 2})$ & $\boldsymbol{P}$ value \\
\hline Vmax $(\mathrm{m} / \mathrm{s})$ & $2.6 \pm 0.5$ & $2.2 \pm 0.5$ & $<.001$ \\
$\mathrm{mPG}(\mathrm{mm} \mathrm{Hg})$ & $15.0 \pm 5.4$ & $10.3 \pm 4.0$ & $<.001$ \\
EOA $\left(\mathrm{cm}^{2}\right)$ & $1.46 \pm 0.35$ & $1.72 \pm 0.46$ & $<.001$ \\
EOAi $\left(\mathrm{cm}^{2} / \mathrm{m}^{2}\right)$ & $0.99 \pm 0.21$ & $1.17 \pm 0.30$ & $<.001$ \\
AR grade & & & $<.001$ \\
0 & $40(55.6)$ & $11(15.3)$ & \\
I & $26(36.1)$ & $28(38.9)$ & \\
II & $6(8.3)$ & $30(41.7)$ & \\
III & $0(0)$ & $3(4.1)$ & \\
IV & $0(0)$ & $0(0)$ & .031 \\
PPM & $19(26.3)$ & $9(12.5)$ & - \\
$19 \mathrm{~mm}$ & $34(47.2)$ & - & - \\
$20 \mathrm{~mm}$ & - & $1(1.4)$ & \\
\hline
\end{tabular}

Values are presented as $\mathrm{n}(\%)$ or mean \pm standard deviation. SAVR, Surgical aortic valve replacement; TAVR, transcatheter aortic valve replacement; $\max$, maximum velocity; $m P G$, mean pressure gradient; $E O A$, effective orifice area; $E O A i$, effective orifice area index; $A R$, aortic regurgitation; $P P M$, patient-prosthesis mismatch. overcome, our results imply that TAVR could be an option to prevent PPM, especially in a patient with a small aortic root.

\section{Study Limitations}

This study has some limitations, which must be noted to interpret the findings of this study precisely. First, this was a single-center and nonrandomized retrospective study with a small number of patients. Second, several incomplete data existed in the SAVR arm because in approximately one-third of SAVR cases, EOA (or EOAi) was not assessed

\footnotetext{
Summary

- Regarding the SAVR arm,

- multivariate analysis revealed that "small ST Junction" was only predictor for PPM.

- Prosthetic valve performances in patients with a small ST Junction (<22.5mm) were inferior to those with the larger ST Junction ( $\geq 22.5 \mathrm{~mm})$.

- Regarding the TAVR arm, there was no significant predictor for PPM

- In the same anatomical characteristics of aortic roots between TAVR and SAVR groups (by a propensity score matching), the prosthetic valve performances in the TAVR group were significantly superior to those in the SAVR group except for aortic regurgitation
}

VIDEO 1. The video shows the background, methods, and results of the present study. Video available at: https://www.jtcvs.org/article/S00225223(18)33253-7/fulltext. 
at discharge or on postoperative day 7. Third, this study lacks midterm or long-term outcomes. Especially, the influence of PPM or mild AR on late outcomes including left ventricular mass regression were not investigated in this study. Fourth, the pressure recovery phenomenon might influence these results to some extent; however, it is challenging to prove the influence of the pressure recovery phenomenon. ${ }^{23}$ Fifth, a significant difference exists in age between the SAVR and TAVR arm patients even after propensity score matching because the age in the TAVR cohort is potentially older than that in the SAVR cohort. Finally, although various types of surgical bioprosthetic valves were included and evaluated in the SAVR arm of this study, only Sapien/Sapien XT was included in the TAVR arm.

\section{CONCLUSIONS}

Preoperative MSCT can predict PPM after SAVR but not TAVR. Especially in patients with a small ST junction, the prevalence of PPM in the SAVR arm of our trial was significantly higher than that in the TAVR arm (Video 1).

\section{Conflict of Interest Statement}

Authors have nothing to disclose with regard to commercial support.

\section{References}

1. Pibarot P, Weissman NJ, Stewart WJ, Hahn RT, Lindman BR, McAndrew T, et al. Incidence and sequelae of prosthesis-patient mismatch in transcatheter versus surgical valve replacement in high-risk patients with severe aortic stenosis: a PARTNER trial cohort-a analysis. J Am Coll Cardiol. 2014;64:1323-34.

2. Dumesnil JG, Pibarot P. Prosthesis-patient mismatch: an update. Curr Cardiol Rep. 2011;13:250-7.

3. Fallon JM, DeSimone JP, Brennan JM, O’Brien S, Thibault DP, DiScipio AW, et al. The incidence and consequence of prosthesis-patient mismatch after surgical aortic valve replacement. Ann Thorac Surg. 2018;106:14-22.

4. Miyasaka M, Tada N, Taguri M, Kato S, Enta Y, Otomo T, et al. Incidence, predictors, and clinical impact of prosthesis-patient mismatch following transcatheter aortic valve replacement in asian patients: the OCEAN-TAVI registry. JACC Cardiovasc Interv. 2018;11:771-80.

5. Mannacio V, Mannacio L, Mango E, Antignano A, Mottola M, Caparrotti S, et al. Severe prosthesis-patient mismatch after aortic valve replacement for aortic stenosis: analysis of risk factors for early and long-term mortality. J Cardol. 2017;69:333-9.

6. Dayan V, Vignolo G, Soca G, Paganini JJ, Brusich D, Pibarot P. Predictors and outcomes of prosthesis-patient mismatch after aortic valve replacement. JACC Cardiovasc Imag. 2016;9:924-33.

7. Jilaihawi H, Kashif M, Fontana G, Furugen A, Shiota T, Friede G, et al. Cross-sectional computed tomographic assessment improves accuracy of aortic annular sizing for transcatheter aortic valve replacement and reduces the incidence of paravalvular aortic regurgitation. J Am Coll Cardiol. 2012;59: 1275-86.

8. Delgado V, Ng AC, van de Veire NR, van der Kley F, Schuijf JD, Tops LF, et al. Transcatheter aortic valve implantation: role of multi-detector row computed tomography to evaluate prosthesis positioning and deployment in relation to valve function. Eur Heart J. 2010;31:1114-23.

9. Pibarot P, Dumesnil JG. Hemodynamic and clinical impact of prosthesis-patient mismatch in the aortic valve position and its prevention. J Am Coll Cardiol. 2000; 36:1131-41.

10. Bourguignon T, Bouquiaux-Stablo AL, Candolfi P, Mirza A, Loardi C, May MA et al. Very long-term outcomes of the Carpentier-Edwards Perimount valve in aortic position. Ann Thorac Surg. 2015;99:831-7.

11. Gao G, Wu Y, Grunkemeier GL, Furnary AP, Starr A. Durability of pericardial versus porcine aortic valves. J Am Coll Cardiol. 2004;44:384-8.

12. Dvir D, Webb JG. Transcatheter aortic valve-in-valve implantation for patients with degenerative surgical bioprosthetic valves. Circ J. 2015;79:695-703.

13. Dvir D, Webb JG, Bleiziffer S, Pasic M, Waksman R, Kodali S, et al Transcatheter aortic valve implantation in failed bioprosthetic surgical valves. JAMA. 2014;312:162-70.

14. Iino K, Miyata H, Motomura N, Watanabe G, Tomita S, Takamura H, et al. Prolonged cross-clamping during aortic valve replacement is an independent predictor of postoperative morbidity and mortality: analysis of the Japan cardiovascular surgery database. Ann Thorac Surg. 2017;103:602-9.

15. Kapadia SR, Leon MB, Makkar RR, Tuzcu EM, Svensson LG, Kodali S, et al. 5-year outcomes of transcatheter aortic valve replacement compared with standard treatment for patients with inoperable aortic stenosis (PARTNER 1): a randomised controlled trial. Lancet. 2015;385:2485-91.

16. Mack MJ, Leon MB, Smith CR, Miller DC, Moses JW, Tuzcu EM, et al. 5-year outcomes of transcatheter aortic valve replacement or surgical aortic valve replacement for high surgical risk patients with aortic stenosis (PARTNER 1): a randomised controlled trial. Lancet. 2015;385:2477-84.

17. Makkar RR, Fontana GP, Jilaihawi H, Kapadia S, Pichard AD, Douglas PS, et al Transcatheter aortic-valve replacement for inoperable severe aortic stenosis. N Engl J Med. 2012;366:1696-704.

18. Kodali SK, Williams MR, Smith CR, Svensson LG, Webb JG, Makkar RR, et al Two-year outcomes after transcatheter or surgical aortic-valve replacement. N Engl J Med. 2012;366:1686-95.

19. Reardon MJ, Kleiman NS, Adams DH, Yakubov SJ, Coselli JS, Deeb GM, et al Outcomes in the randomized CoreValve US pivotal high-risk trial in patients with a Society of Thoracic Surgeons risk score of 7\% or less. JAMA Cardiol. 2016;1 945-9.

20. Leon MB, Smith CR, Mack MJ, Makkar RR, Svensson LG, Kodali SK, et al Transcatheter or surgical aortic-valve replacement in intermediate-risk patients. N Engl J Med. 2016;374:1609-20.

21. Clavel MA, Webb JG, Pibarot P, Altwegg L, Dumont E, Thompson C, et al Comparison of the hemodynamic performance of percutaneous and surgical bioprostheses for the treatment of severe aortic stenosis. J Am Coll Cardiol. 2009;53:1883-91.

22. Amat-Santos IJ, Dahou A, Webb J, Dvir D, Dumesnil JG, Allende R, et al. Comparison of hemodynamic performance of the balloon-expandable SAPIEN 3 versus SAPIEN XT transcatheter valve. Am J Cardiol. 2014;114:1075-82.

23. Mohan JC, Mohan V, Shukla M, Sethi A. Significant intra-valvular pressure loss across EPIC SUPRA and perimount magna supra-annular designed aortic bioprostheses in patients with normal aortic size. Indian Heart J. 2017; 69:87-92.

Key Words: aortic valve stenosis, patient-prosthesis mismatch, multislice computed tomography 


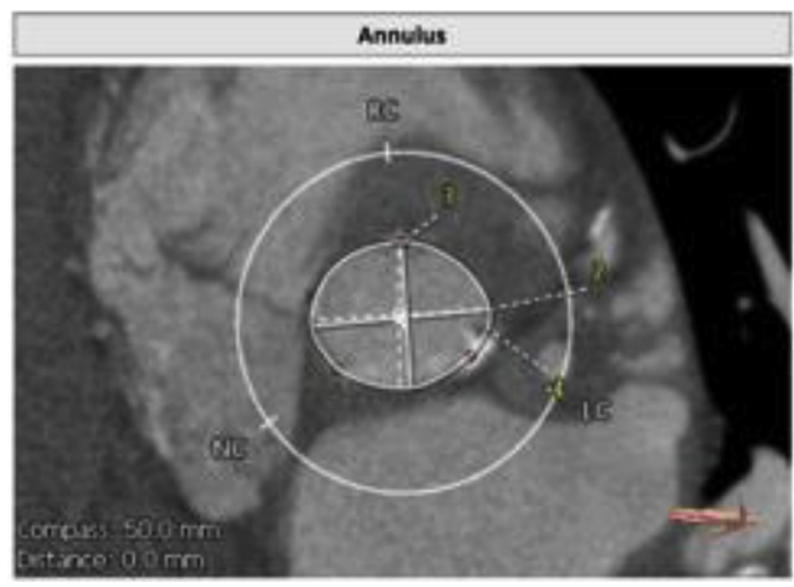

FIGURE E1. After the automated reconstruction and segmentation of the aortic root, the annular plane was identified in a perpendicular short-axis view, defined as the plane connecting the nadirs of all 3 aortic cusps. Next, a polygonal line circumscribing a basal ring was traced to define its perimeter. The annulus diameter was evaluated as ([perimeter of the traced polygon $] / \pi$ ), as described previously at the annular plane in systole. Computed tomography images were assessed by a dedicated workstation with the 3 mensio valve software (3mensio Medical Imaging BV, Bilthoven, The Netherlands).

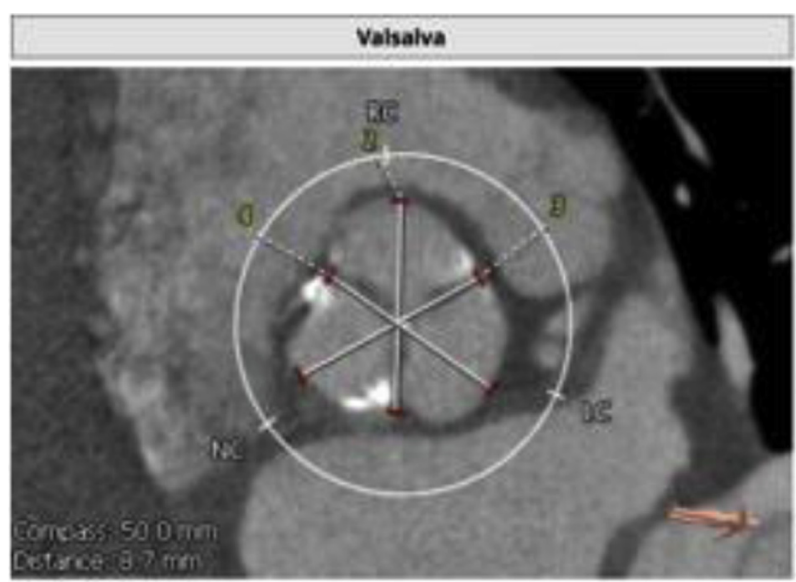

FIGURE E2. We defined the sinus of the Valsalva plane as the plane perpendicular to the center line that exhibits the largest cusp dimensions and evaluated the Valsalva diameter as the mean diameter of three sinuses in diastole. Computed tomography images were assessed by a dedicated workstation with the 3 mensio valve software (3mensio Medical Imaging BV, Bilthoven, The Netherlands).

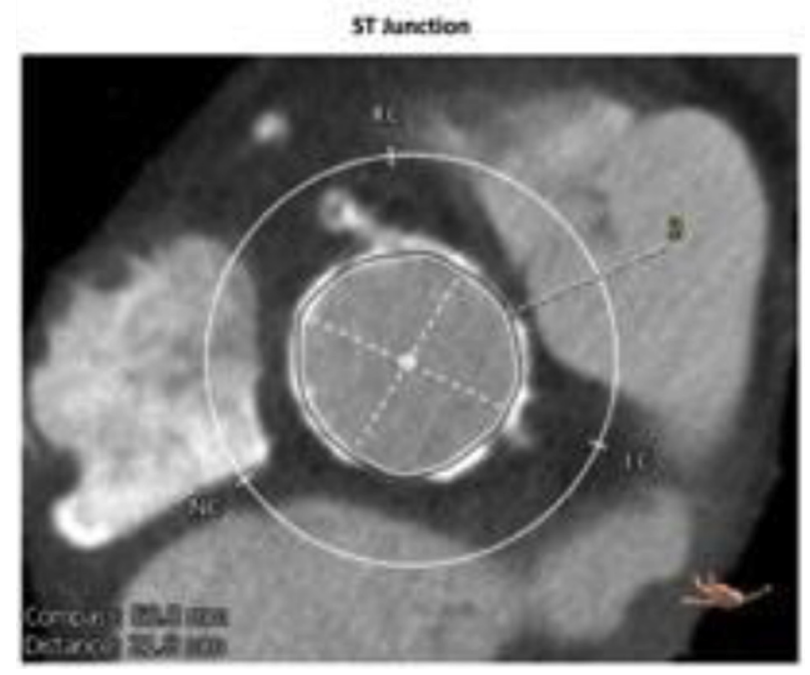

FIGURE E3. The sinotubular junction plane was defined as the distal end of the sinus portion. Furthermore, we evaluated the sinotubular junction diameter as ([perimeter of the traced polygon] $/ \pi$ ) at the sinotubular junction plane in diastole. Computed tomography images were assessed by a dedicated workstation with the 3 mensio valve software (3mensio Medical Imaging BV, Bilthoven, The Netherlands).

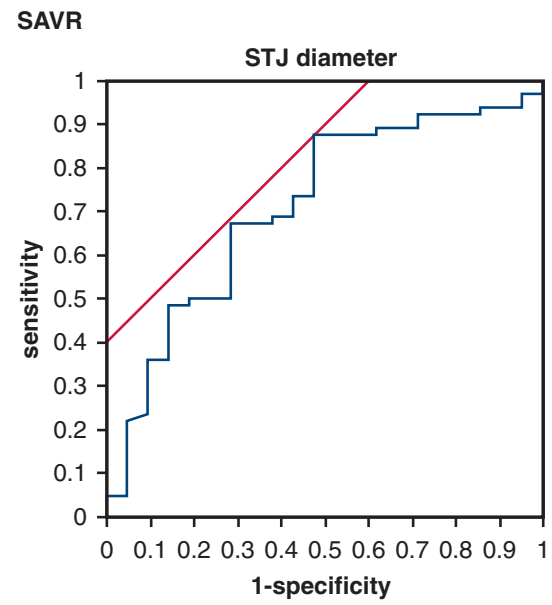

$\mathrm{AUC}=0.71 ; P=.0072 ;$ cut-off $=22.5$ Sensitivity, $87.5 \%$; Specificity, $52.4 \%$

FIGURE E4. The receiver-operating characteristic analysis of the correlation between the sinotubular junction diameter on the computed tomography findings and the incidence of patient-prosthesis mismatch in the surgical aortic valve replacement arm. The cutoff value of $22.5 \mathrm{~mm}$ in the sinotubular junction diameter on the computed tomography findings exhibited the highest sum of sensitivity $(87.5 \%)$ and specificity (52.4\%; area under the curve, 0.71$)$. 


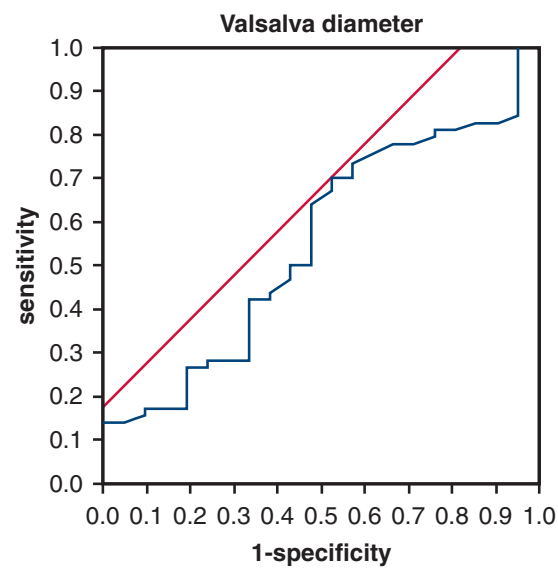

AUC $=0.55 ; P=.39 ;$ cut-off $=27.6$

Sensitivity, $70.3 \%$; Specificity, $47.6 \%$

FIGURE E5. Receiver-operating characteristics analysis of Valsalva diameter, surgical aortic valve replacement arm. Area under the curve, $0.55 ; P=.39 ;$ cutoff $=27.6$; sensitivity, $70.3 \%$; specificity, $47.6 \%$.

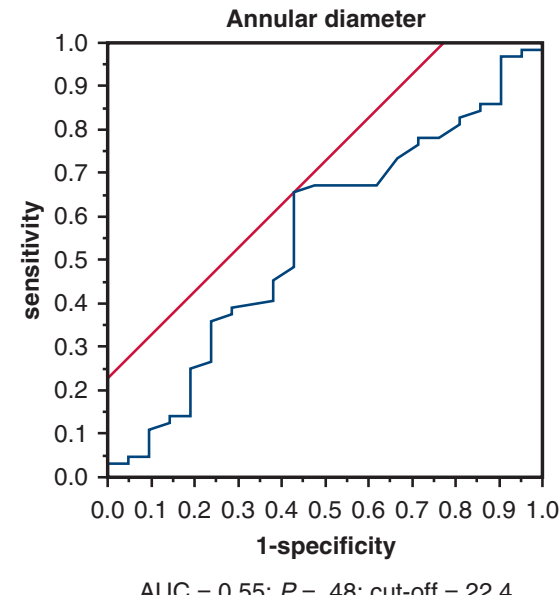

Sensitivity, $65.6 \%$; Specificity, $57.1 \%$

FIGURE E6. Receiver-operating characteristics analysis of annular diameter, surgical aortic valve replacement arm. Area under the curve, $0.55 ; P=.48$; cutoff, 22.4 ; sensitivity, $65.6 \%$; specificity, $57.1 \%$.

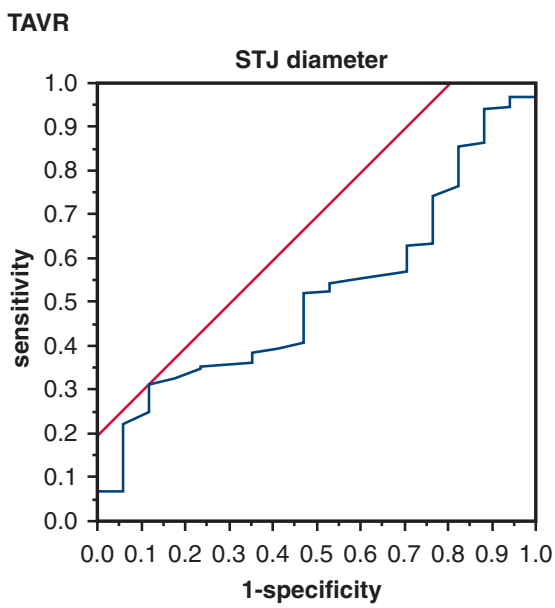

$\mathrm{AUC}=0.52 ; P=.69 ;$ cut-off $=23.7$ Sensitivity, $31.2 \%$; Specificity, $88.2 \%$

FIGURE E7. Receiver operator characteristics analysis of anatomy of the aortic root: Sinotubular junction diameter, transcatheter aortic valve arm. Area under the curve, $0.52 ; P=.69$; cutoff, 23.7 ; sensitivity, $31.2 \%$; specificity, $88.2 \%$.

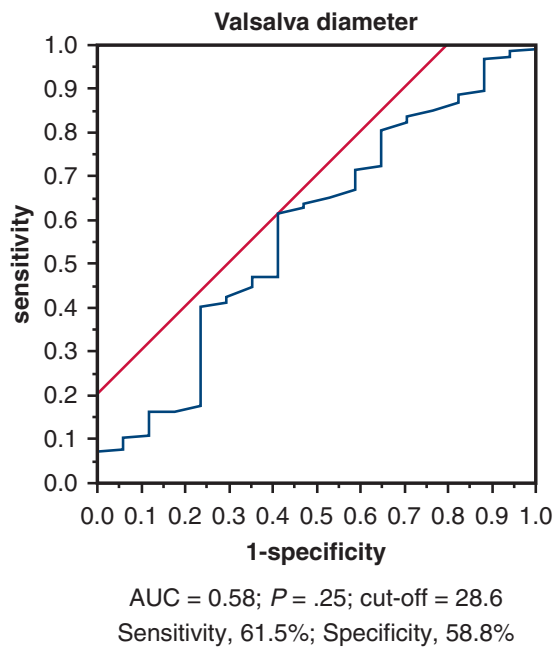

FIGURE E8. Receiver operator characteristics analysis of anatomy of the aortic root: Valsalva diameter, transcatheter aortic valve arm. Area under the curve, $0.58 ; P=.25$; cutoff, 28.6 ; sensitivity, $61.5 \%$; specificity, $58.8 \%$. 


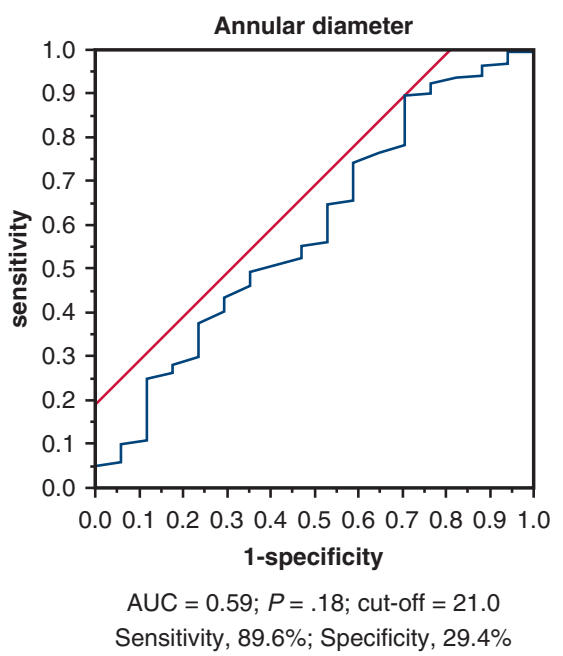

FIGURE E9. Receiver operator characteristics analysis of anatomy of the aortic root: Annular diameter, transcatheter aortic valve arm. Area under the curve, $0.59 ; P=.18$; cutoff, 21.0 ; sensitivity, $89.6 \%$; specificity, $29.4 \%$.
TABLE E1. The annular diameter and the incidence of patientprosthesis mismatch (PPM), according to bioprosthesis size

\begin{tabular}{|c|c|c|}
\hline Valve* & Annular diameter (mm) & Incidence of PPM \\
\hline Mosaic $(n=33)$ & $22.5(21.9-24.0)$ & $10(30.3)$ \\
\hline 19 mm (n = 19) & $22.0(20.6-22.8)$ & $7(36.8)$ \\
\hline $21 \mathrm{~mm}(\mathrm{n}=10)$ & $23.6(22.2-24.1)$ & $3(30.0)$ \\
\hline $23 \mathrm{~mm}(\mathrm{n}=3)$ & $24.4(23.1-24.8)$ & $0(0)$ \\
\hline $25 \mathrm{~mm}(\mathrm{n}=1)$ & 26.7 (26.7-26.7) & $0(0)$ \\
\hline $\operatorname{CEP}(n=22)$ & $23.7(22.3-24.7)$ & $5(22.7)$ \\
\hline 19 mm $(\mathrm{n}=7)$ & $21.3(20.7-23.2)$ & $4(57.1)$ \\
\hline $21 \mathrm{~mm}(\mathrm{n}=11)$ & $24.2(23.6-24.6)$ & $1(9.1)$ \\
\hline $23 \mathrm{~mm}(\mathrm{n}=3)$ & $26.4(23.3-28.8)$ & $0(0)$ \\
\hline $25 \mathrm{~mm}(\mathrm{n}=1)$ & $27.7(27.7-27.7)$ & $0(0)$ \\
\hline Mitroflow $(\mathrm{n}=7)$ & $21.0(20.9-22.7)$ & $2(28.6)$ \\
\hline 19 mm (n=3) & $20.9(19.6-21.0)$ & $1 / 3(33.3)$ \\
\hline $21 \mathrm{~mm}(\mathrm{n}=4)$ & $22.3(21.2-22.8)$ & $1 / 4(25.0)$ \\
\hline Epic $(n=12)$ & $24.7(21.3-25.8)$ & $2(16.7)$ \\
\hline $19 \mathrm{~mm}(\mathrm{n}=5)$ & $21.1(20.5-22.6)$ & $1(20.0)$ \\
\hline $21 \mathrm{~mm}(\mathrm{n}=4)$ & $25.6(24.3-26.2)$ & $0(0)$ \\
\hline $23 \mathrm{~mm}(\mathrm{n}=3)$ & $25.5(25.4-29.4)$ & $1(33.3)$ \\
\hline Trifecta $(\mathrm{n}=11)$ & $23.6(21.9-25.3)$ & $2(18.2)$ \\
\hline $19 \mathrm{~mm}(\mathrm{n}=4)$ & $21.6(21.2-22.0)$ & $1(25.0)$ \\
\hline $21 \mathrm{~mm}(\mathrm{n}=7)$ & $24.9(23.6-25.7)$ & $1(14.3)$ \\
\hline Sapien $(n=41)$ & $23.4(22.0-24.9)$ & $4(9.8)$ \\
\hline $23 \mathrm{~mm}(\mathrm{n}=27)$ & $22.7(21.5-23.4)$ & $2(7.4)$ \\
\hline $26 \mathrm{~mm}(\mathrm{n}=14)$ & $25.1(24.3-25.8)$ & $2(14.3)$ \\
\hline Sapien XT $(\mathrm{n}=197)$ & $22.7(21.5-23.9)$ & $13(6.6)$ \\
\hline $20 \mathrm{~mm}(\mathrm{n}=1)$ & $18.4(18.4-18.4)$ & $0(0)$ \\
\hline $23 \mathrm{~mm}(\mathrm{n}=116)$ & $21.9(21.2-22.8)$ & $10(8.6)$ \\
\hline $26 \mathrm{~mm}(\mathrm{n}=73)$ & $23.8(23.0-24.9)$ & $3(4.1)$ \\
\hline $29 \mathrm{~mm}(\mathrm{n}=7)$ & $27.2(26.7-28.1)$ & $0(0)$ \\
\hline \multicolumn{3}{|c|}{$\begin{array}{l}\text { Values are presented as median (interquartile range) or } \mathrm{n}(\%) . P P M, \\
\text { Patient-prosthesis mismatch; CEP, Carpentier-Edwards Perimount valve. } \\
\text { *Device manufacturers: Mosaic: Medtronic Inc, Minneapolis, Minn; CEP: Edwards } \\
\text { Lifesciences, Irvine, Calif; Epic Valve: Abbott-St Jude Medical, St Paul, Minn; } \\
\text { Trifecta Valve: Abbott-St Jude Medical; Mitroflow: Sorin Group Inc, Saluggia, Italy; } \\
\text { Sapien: Edwards Lifesciences; Sapien XT: Edwards Lifesciences. }\end{array}$} \\
\hline
\end{tabular}


TABLE E2. Baseline characteristics of patients in the transcatheter aortic valve replacement (TAVR) and surgical aortic valve replacement (SAVR) arms, according to presence (+) or absence (-) of patient-prosthesis mismatch (PPM)

\begin{tabular}{|c|c|c|c|c|c|c|}
\hline \multirow[b]{2}{*}{ Characteristic } & \multicolumn{3}{|c|}{$\operatorname{SAVR}(\mathbf{n}=\mathbf{8 5})$} & \multicolumn{3}{|c|}{$\operatorname{TAVR}(\mathbf{n}=\mathbf{2 3 8})$} \\
\hline & $\overline{\mathbf{P P M}(+)(\mathbf{n}=\mathbf{2 1})}$ & PPM (-) $(n=64)$ & $P$ value & $\overline{\mathbf{P P M}(+)(\mathbf{n}=\mathbf{1 7})}$ & PPM (-) $(\mathbf{n}=221)$ & $P$ value \\
\hline Age $(y)$ & $75.9 \pm 4.5$ & $75.9 \pm 6.1$ & .999 & $83.1 \pm 5.1$ & $83.0 \pm 6.1$ & .955 \\
\hline Female sex & $16(76.2)$ & $39(60.9)$ & .294 & $12(70.6)$ & $142(64.3)$ & .793 \\
\hline $\operatorname{BSA}\left(\mathrm{m}^{2}\right)$ & $1.46 \pm 0.14$ & $1.49 \pm 0.18$ & .450 & $1.49 \pm 0.11$ & $1.42 \pm 0.17$ & .110 \\
\hline BMI & $23.3 \pm 4.8$ & $22.0 \pm 3.6$ & .202 & $22.1 \pm 2.9$ & $21.5 \pm 3.3$ & .463 \\
\hline \multicolumn{7}{|c|}{ Preoperative echocardiography findings } \\
\hline $\operatorname{Vmax}(\mathrm{m} / \mathrm{s})$ & $4.4 \pm 0.7$ & $4.6 \pm 0.7$ & .179 & $4.5 \pm 0.7$ & $4.5 \pm 0.7$ & .750 \\
\hline mPG (mm Hg) & $47.6 \pm 16.2$ & $53.8 \pm 16.9$ & .147 & $50.9 \pm 16.3$ & $49.9 \pm 17.7$ & .819 \\
\hline $\operatorname{AVA}\left(\mathrm{cm}^{2}\right)$ & $0.75 \pm 0.19$ & $0.75 \pm 0.17$ & .990 & $0.65 \pm 0.17$ & $0.68 \pm 0.18$ & .475 \\
\hline AVAi $\left(\mathrm{cm}^{2} / \mathrm{m}^{2}\right)$ & $0.51 \pm 0.12$ & $0.50 \pm 0.12$ & .832 & $0.44 \pm 0.11$ & $0.48 \pm 0.12$ & .137 \\
\hline AR grade $\geq$ II & $12(57.1)$ & $40(62.5)$ & .797 & $14(82.3)$ & $163(73.8)$ & .571 \\
\hline $\mathrm{EF}(\%)$ & $63.5 \pm 10.0$ & $66.1 \pm 10.3$ & .322 & $59.2 \pm 16.5$ & $61.6 \pm 13.1$ & .475 \\
\hline \multicolumn{7}{|l|}{ ECG-gated MSCT findings } \\
\hline Annular diameter (mm) & $22.9 \pm 2.3$ & $23.3 \pm 2.1$ & .492 & $22.4 \pm 1.8$ & $23.0 \pm 1.8$ & .195 \\
\hline Valsalva diameter (mm) & $28.8 \pm 2.9$ & $29.5 \pm 3.9$ & .404 & $28.8 \pm 2.8$ & $29.6 \pm 2.7$ & .266 \\
\hline ST junction diameter $(\mathrm{mm})$ & $23.5 \pm 2.8$ & $25.6 \pm 3.3$ & .011 & $25.3 \pm 2.2$ & $25.1 \pm 2.7$ & .692 \\
\hline \multicolumn{7}{|l|}{ Procedure-related variable } \\
\hline Concomitant procedure & $9(42.9)$ & $25(39.1)$ & .801 & $0(0)$ & $7(3.2)$ & 1.0 \\
\hline
\end{tabular}

Values are presented as n (\%) or mean \pm standard deviation. SAVR, Surgical aortic valve replacement; TAVR, transcatheter aortic valve replacement; $P P M$, patient-prosthesis mismatch; $B S A$, body surface area; $B M I$, body mass index; Vmax, maximum velocity; $m P G$, mean pressure gradient; $A V A$, aortic valve area; $A V A i$, aortic valve area index; $A R$, aortic regurgitation; $E F$, ejection fraction; $E C G$, electrocardiogram; $M S C T$, multislice computed tomography; $S T$, sinotubular junction. 